\title{
Incubadoras de empresas, inovação tecnológica e ação governamental: o caso de Santa Rita do Sapucaí (MG)
}

\author{
Simone Abreu Ribeiro* \\ Raphael Medina Gomes de Andrade** \\ André Luiz Zambalde***
}

\section{Resumo}

0 processo de difusão de novas tecnologias tem transformado o atual cenário empresarial, uma vez que ameaça a sobrevivência de empresas e promove novos mercados. Para enfrentar novos desafios, portanto, empresas apóiam-se na inovação tecnológica para capturar mercados e criar vantagens competitivas. Entretanto, a despeito desse esforço, é necessário o incentivo por parte do Poder Público nas empresas.

0 presente artigo trata de um estudo de caso realizado num município inovador (Santa Rita do Sapucaí, parte integrante do "Vale da Eletrônica"), objetivando compreender o papel do Poder Público na promoção da inovação tecnológica em uma incubadora de empresas. A pesquisa conclui que a parceria entre o Poder Público e a incubadora de empresas pode ser uma tentativa de amenizar o problema de desemprego estrutural vivenciado no Brasil, além de propiciar vantagens para as empresas abrigadas e para a economia da região, uma vez que produz pesquisa e desenvolvimento econômico e social.

Palavras-Chave: Inovação tecnológica; Poder Público; Incubadoras de Empresas e Vantagem Competitiva

\begin{abstract}
The process of diffusion of new technologies has transformed the current managerial scenery, threatening the survival of companies promoting promotes new markets, and making accumulated competences obsoletc. To face new challenges, therefore, companies draw on the technological innovation to capture markets and to create competitive advantages. However, despite of such effort, government support is also necessary. The present article is based on a case study of the innovative municipal district of Santa Rita do Sapucaí, in the Southeastern state of Minas Gerais, part of the "Electronics Valley". The article aims at generating understanding of the Role of government of the government in promoting technological innovation in an incubator of companies. The research concludes that the partnership between government and the incubator of companies can be an attempt to softening the problem of structural unemployment in Brazil, besides providing advantages for the sheltered companies and for the economy of the area, once it produces research and economical and social development.
\end{abstract}

Key-words: Technological innovation; public power; incubator of companies and competitive advantage

\footnotetext{
* Graduada em Administração de empresas da Universidade Federal de Lavras (UFLA). E-mail: Simone_ufla@ yahoo.com.br. Endereço: Alameda dos Ipês 229 - Cond. Jardim das Palmeiras - Lavras MG - CEP: 37200-000

** Mestrando da Universidade de Utrecht. E-mail: medinaraphael@ uol.com.br. Endereço: Rua Ministro Correia de Melo, 70 Apt:a1702 - Leblon - Rio de Janeiro-RJ CEP: 22430-110

*** Professor adjunto da Universidade Federal de Lavras/MG (UFLA) no Departamento de Ciência da Computação. E-mail: zamba@ ufla.br. Endereço: Caixa Postal 3037 CEP: 37200-000 Lavras- MG

Artigo aceito para publicação em novembro de 2004 e aceito em março de 2005.
} 


\section{Introdução}

Hoje em dia, a dinâmica de desenvolvimento da economia mundial vem sendo fortemente influenciada pela consolidação de um novo paradigma técnico-econômico, no qual a globalização da economia leva o setor produtivo a um esforço crescente pela competitividade. Nesse contexto, o binômio inovação/competitividade é fundamental para a modernização do parque produtivo nacional, visando à ampliação de sua participação no comércio internacional. Portanto, é necessário que as organizações definam, de forma clara, concisa e objetiva, suas estratégias e planos de desenvolvimento da gestão tecnológica, a qual não pode mais ser implementada nos moldes e estruturas hierárquicas tradicionais. Cada vez mais, é indispensável enfocar a gestão tecnológica como parte da estratégia competitiva empresarial. Segundo Porter (1990), a gestão tecnológica é um dos elementos fundamentais das vantagens competitivas, por seu caráter cumulativo e por ser grande geradora de valor.

No Brasil, o processo de modernização começou na década de 1980, num ambiente de abertura política e sob a égide da automação de base microeletrônica. A partir dos anos 1990, com a liberalização dos mercados, o processo de mudanças (gerencial e tecnológica) assumiu grandes proporções. Com a nova estrutura de concorrência, tornou-se obrigatório um novo padrão de produtividade e qualidade, definido pela combinação de ciência com tecnologia. Em mercados globalizados, a competitividade é determinada pela capacidade de crescimento diante dos melhores concorrentes internacionais e, sobretudo, pela capacidade sistêmica de organização e coordenação das inovações tecnológicas, a partir das formas de governança exercidas entre os diferentes agentes que constituem as empresas. Dessa forma, o que pôde ser constatado após a abertura econômica, foi que muitas empresas nacionais não sobreviveram, pois não tinham uma visão sistêmica e, conseqüentemente, não estavam capacitadas a coordenar inovações tecnológicas de maneira eficiente.

Passada essa fase, as empresas brasileiras vêm desenvolvendo esforços crescentes para vencer os desafios. Cada vez mais, ser competitivo e inovar tecnologicamente depende de conhecimento e organização do aprendizado (CASSIOLATO \& LASTRES, 2000). A estratégia fundamental para ganhar competitividade está na capacidade de inovar, portanto, as empresas que não forem constantemente inovadoras tendem a não sobreviver.

A inovação é cada vez mais importante para o desenvolvimento socioeconômico dos mais diversos países, os quais reconhecem que, para melhorar e ampliar suas estruturas industriais e de exportação, são necessárias medidas cuidadosamente formuladas para estimular atividades de ciência e tecnologia articuladas com as demandas do setor produtivo.

Diante desse cenário, tornam-se necessárias políticas públicas de incentivo à ciência e tecnologia $(\mathrm{C} \& \mathrm{~T})$ e à pesquisa e desenvolvimento (P\&D), envolvendo os diversos níveis do poder público. Diversas empresas, principalmente as iniciantes, não teriam as condições técnicas e científicas, ou mesmo financeiras, necessárias para se tornarem produtivas e adquirir solidez neste mercado competitivo. Nesse caso, é preciso uma parceria entre o poder público e as empresas, visando à inovação tecnológica.

O objetivo deste artigo é justamente analisar o papel do poder público na promoção da inovação tecnológica, baseado em um estudo exploratório do Programa Municipal de Incubação Avançada de Empresas de Base Tecnológica, em Santa Rita do Sapucaí (MG), município integrante do "Vale da Eletrônica". Mais especificamente, serão destacados os fatores que levaram esse município a se tornar um pólo tecnológico reconhecido internacionalmente, atraindo, inclusive, investimentos estrangeiros. 


\section{Referencial teórico}

\subsection{Inovação tecnológica}

Para Betz (1993), a inovação tecnológica pode ser definida como o processo de criação, desenvolvimento e colocação no mercado de produtos ou serviços que incorporam novas tecnologias. Para o autor, as inovações tecnológicas podem alterar diversas características dos produtos ou dos sistemas produtivos da empresa, garantindo vantagem competitiva.

Conforme a Organização para Cooperação e Desenvolvimento Econômico (ORGANIZATION FOR ECONOMIC COOPERATION AND DEVELOPMENT - OECD 1992 apud Reis (2004)), inovações tecnológicas incluem novos produtos, processos, serviços e também mudanças tecnológicas em produtos, processos e serviços existentes. Uma inovação é implementada se for introduzida no mercado (inovações de produto) ou for usada dentro de um processo de produção (inovação de processo). Inovações envolvem então uma série de atividades científicas, tecnológicas, organizacionais, financeiras e comerciais.

De acordo com Lacerda (2001), a inovação tecnológica, como um bem econômico, tornou-se instrumento fundamental na criação de novos negócios e novos postos de trabalho que permitam o desenvolvimento econômico sustentável nos países e a geração de riqueza nas empresas. Estas, pela necessidade de geração contínua de inovações, se vêem diante do desafio de mudar radicalmente seus modelos de gestão:

- tratando a informação como um insumo intensivo;

- flexibilizando os processos produtivos;

- promovendo a "horizontalização" e a integração de áreas;

- incentivando a permanente troca de informação entre funcionários e

- valendo-se do uso intensivo de tecnologia.

Para Cassiolato \& Lastres (2000), nos últimos anos, chegou-se a um consenso em relação a alguns aspectos que envolvem o processo de inovação, dentre os quais, o de que:

- a inovação é um processo de busca e aprendizado que, na medida em que depende de interações, é socialmente determinado e fortemente influenciado por formatos institucionais e organizacionais específicos, como a diversidade regional, as especificidades locais etc.;

- todos os agentes ou atores da inovação tecnológica têm a mesma capacidade de transferir e assimilar tecnologicamente, já que dependem de aprendizados anteriores, assim como da própria capacidade de esquecer e reaprender tecnologias; $\mathrm{e}$

- existem importantes diferenças entre sistemas de inovação de países, regiões, organizações; em função de cada contexto social, político e institucional. As próprias diferenças regionais do Brasil são um exemplo.

Assim, o processo de inovação tecnológica assume características específicas, dependendo da região, do nível das instituições que o comportam e do próprio processo de articulação entre os atores da inovação, que são as empresas, universidades, centros de pesquisas, órgãos de ciência e tecnologia, incubadoras de empresas, condomínios empresariais, parques tecnológicos e organizações não-governamentais, entre outros.

Para os sistemas nacionais de inovação, os atores econômicos, sociais e as relações entre eles determinam, em grande medida, a capacidade de aprendizado de um país ou região, assim como a experiência histórica e cultural, a educação e o desenvolvimento tecnológico. Os sistemas nacionais, regionais ou locais de inovação podem ser considerados como uma rede de instituições dos setores públicos (instituições de pesquisa e universidades, agências governamentais de fomento e financiamento, empresas estatais e incubadoras, entre outros) e privado (empresas, associações empresariais, sindicatos, organizações não-governamentais e incubadoras), cujas atividades e interações geram, adotam, importam, modificam e difundem novas tecnologias, sendo a inovação e o aprendizado seus aspectos cruciais. 
Dessa forma, o processo de inovação é interativo e dependente dos atores envolvidos e da capacidade de apreender, gerar e absorver conhecimentos; bem como da articulação dos agentes e fontes de inovação e do nível de conhecimento alcançado.

\subsection{A inovação tecnológica como agente propulsor de desenvolvimento das nações}

Pesquisas apontam que, de uma perspectiva estratégica, a ciência e tecnologia é uma prática que efetivamente contribui para o desenvolvimento industrial das nações. Uma gama considerável de autores defende seu uso para se atingir objetivos estratégicos e garantir vantagens competitivas representadas pelo desenvolvimento de novos produtos e equipamentos, de novos processos de produção e distribuição e de novas estruturas organizacionais adequadas aos novos produtos e processos (FREEMAN \& SOETE, 1997; PORTER, 1990; BELL \& PAVITT, 1993).

As políticas públicas podem ser vistas como ações efetivadas de forma consciente e planejada pelos governos, em qualquer nível hierárquico, visando resolver problemas ou implantar mecanismos de prevenção, estímulo ou controle de instituições ou setores que exerçam influência na sociedade ou no próprio poder público. Nesse contexto, as políticas públicas podem ser vistas como sistemas de decisões governamentais, traduzidas em ações corretivas ou preventivas, cujo objetivo envolve a manutenção ou a modificação da realidade de um, vários ou de todos os setores da vida social.

Ao tratar dessa temática, Freeman \& Soete (1997) também são favoráveis a uma estrutura em que o suporte a alguns elementos da ciência e tecnologia - principalmente, a pesquisa e desenvolvimento - devem ser priorizados pelos governos, em todos os níveis hierárquicos. Para os autores, estão incluídos como elementos da estrutura de C\&T, a pesquisa (básica, aplicada e de desenvolvimento), a engenharia e as instituições e agências de fomento, entre outros.

Para corroborar esses argumentos, Salles \& Hasenclever (1999) afirmam que mesmo dispondo-se de outras fontes de suporte (como os fundos privados), é justificável o suporte governamental para a pesquisa e desenvolvimento. $\mathrm{O}$ investimento público garante a expansão das pesquisas, a difusão e a assimilação do conhecimento, além do intercâmbio entre empresas, universidades e centros de pesquisas. Contudo, o suporte governamental não ser direcionado apenas para a indústria, mas também para os setores de alto significado social, como os de educação, da saúde e do meio ambiente.

De uma perspectiva mais ampla, podemos dizer que a criação de políticas tecnológicas em um país ou entre países visa construir redes calcadas em relações técnicas e econômicas entre as empresas e entre as universidades e instituições tecnológicas e científicas. De uma perspectiva micro, a tecnologia pode ser considerada como um conjunto de práticas empregadas na sequiência das atividades que constituem a cadeia de valores de uma empresa. Ambas as perspectivas preocupam-se com a relação entre o processo de inovação e a construção das vantagens competitivas dos países. Daí a importância das políticas governamentais para a criação de infra-estruturas científicas e tecnológicas e para o fortalecimento das networks. (DENIOZOS, 1994; PORTER, 1989; PORTER, 1990; GOUSSEVSKAIA \& RODRIGUES, 2000).

A formulação de políticas públicas voltadas para a ciência e tecnologia não deve estar restrita à definição de percentual de gastos em pesquisa básica e em pesquisa e desenvolvimento industrial. Também não deve contemplar gastos estratégicos visando apenas compensar eventuais atrasos em P\&D de áreas sociais, como meio ambiente, segurança e saúde. Qualquer política pública adequada deverá ter como condição sine qua non, uma variável de caráter qualitativo que estabeleça prioridades quanto aos objetivos de ciência e tecnologia das áreas de governo. De outra forma, não se conseguirá um desenvolvimento sustentável que preserve a qualidade de vida e o meio ambiente.

\subsection{Sistemas de inovações tecnológicas e o papel do setor público}

A motivação do poder público em fomentar diversas atividades relacionadas à inovação tecnológica não deve ser considerada, exclusivamente, como um esforço para melhorar as condições de produção em setores específicos. No caso brasileiro, a Lei de Competitividade em Tecnologia da Informação direcionada a Zona 
Franca de Manaus (Lei no. 8.387/91) e a Lei de Informática e automação (Lei no. 8.248/91) que tiveram alguns de seus artigos alterados e atualizados pela Lei 10.176/01 (Capacitação e competitividade no setor de Tecnologia da Informação), alem da Lei de Inovação (Lei no. 10.973/2004) buscam produzir um efeito sinérgico de estímulo à pesquisa, ao desenvolvimento tecnológico e à inovação, por intermédio do relacionamento entre universidades, centros de pesquisas, órgãos públicos e empresas (BRASIL, 2004). Dessas leis e dos fundos de promoção a um sistema de inovação baseado nas possibilidades de desenvolvimento das diferentes regiões do Brasil, e do país em seu conjunto, os resultados de maior impacto são:

- o retorno social dos investimentos, com a conseqüente redução das desigualdades sociais e regionais;

- a consolidação de uma base cientifica e tecnológica e a capacitação de recursos humanos, resultando numa menor demanda por mão-de-obra não-qualificada;

- alto retorno privado;

- aumento da produtividade quando da inovação em processos, levando à queda dos preços (SÁNCHEZ \& PAULA, 2001; NICOLSKY, 2001; FONSECA, 2001).

A redução da demanda por mão de obra não-qualificada representa, no curto prazo, um problema para o poder público, em todos os seus níveis. No entanto, a ampliação do número de postos de trabalho resultante de novos empreendimentos, se conjugada a programas de educação e qualificação técnica, tende a alocar novos trabalhadores e a realocar antigos em funções melhor remuneradas.

Conforme Mota (2001), tanto nas iniciativas de caráter local, quanto nas de caráter regional e nacional, a necessidade de se coordenar os esforços de agentes oriundos de instâncias públicas e privadas tem motivado o estabelecimento de novos arranjos institucionais. Da combinação desses arranjos e do estabelecimento de novas competências é que se originam os sistemas de inovação.

Um sistema de inovação pode ser definido como um conjunto de instituições distintas que conjuntamente e individualmente contribuem para o desenvolvimento e difusão de tecnologias. Tal noção envolve, portanto, não apenas empresas, mas, principalmente, instituições de ensino e pesquisa, de financiamento, governo etc. Esse conjunto constitui o quadro de referência no qual o governo forma e implementa políticas visando influenciar o processo inovativo (CASSIOLATO \& LASTRES, 2000, p.247).

A iniciativa de se avaliar o papel do poder público na configuração de sistemas nacionais, regionais ou locais de inovação deve ser precedida de um debate sobre dois aspectos: $O$ primeiro refere-se ao papel dos empreendedores, considerados por alguns estudiosos como sendo a unidade fundamental do desenvolvimento econômico. Já, o segundo aspecto, diz respeito à eficácia das ações governamentais, tanto no que se refere ao fomento direto por meio de investimentos, isenções ou tributações seletivas, quanto ao estímulo indireto através da articulação de agentes públicos e privados.

Uma das referências pioneiras sobre a contribuição do empreendedor e da inovação para o desenvolvimento econômico pode ser encontrada na obra do economista austríaco Joseph A. Schumpeter (1982). Ele atribui extrema importância às "novas combinações de meios de produção" ou "empreendimentos" e aos "empresários", cuja principal função seria realizar tais combinações. Segundo Schumpeter, o que caracteriza um "empresário" não é a posse dos meios de produção, mas, sim, o impulso às inovações.

Em seus estudos, Schumpeter apresenta uma variante ao que denomina "fluxo circular da vida econômica", que considera a variável tecnológica como exógena ao mercado, determinada por processos desconhecidos e crescimento constante ao longo dos anos. Segundo o autor:

(...) ao descrever o fluxo circular deve-se tratar as combinações de meios de produção (as funções de produção) como dados, como possibilidades naturais e admitir apenas variações pequenas na margem, tais que todo indivíduo pode realizar ao adaptar-se às mudanças em seu ambiente econômico, sem 
desviar-se materialmente das linhas habituais. Portanto, a realização de combinações novas é ainda uma função especial e o privilégio de um tipo de pessoa que é muito menos numeroso que todos os que têm possibilidade 'objetiva' de fazê-lo. Portanto, finalmente, os empresários são um tipo especial, e o seu comportamento um problema especial, a força motriz de um grande número de fenômenos significativos (SCHUMPETER, 1982, p.57-58).

Caso a validade da primeira teoria (determinista) fosse absoluta, não haveria qualquer motivação para os empresários investirem em inovações tecnológicas. Em conseqüência, quaisquer iniciativas de caráter público implementadas para incentivar ou desonerar os agentes dispostos a promover inovações seriam totalmente ineficazes. Em outras palavras,

O pressuposto de que as determinantes do crescimento de longo prazo são endógenas ao processo de tomada de decisões da empresa é um desvio importante com relação à teoria neoclássica do crescimento, e tem importantes implicações em termos de políticas. Realmente, se o crescimento de longo prazo é conduzido por fatores de produção baseados no conhecimento que são parte da estrutura normal de custos da empresa, então, mudando-se os custos desses fatores através, por exemplo, de subsídios diretos, incentivos fiscais ou políticas comerciais, os governos podem influenciar o crescimento a longo prazo (MINISTÉRIO DAS FINANÇAS E DA RECEITA DO CANADÁ, 1997).

A constatação de que pode desempenhar um papel determinante no que se refere à propensão de organizações privadas investirem em tecnologia e inovação confere aos gestores públicos novos instrumentos capazes de dinamizar a atividade produtiva de uma região. Segundo Guimarães (2000), às tradicionais políticas fiscal, cambial e monetária foram acrescidos o planejamento dos investimentos públicos, a orientação dos investimentos privados e a política de ciência e tecnologia.

\subsection{Importância das iniciativas municipais para a constituição de sistemas locais de inovação tecnológica}

No Brasil, diversos fatores contribuíram para a emergência de iniciativas de desenvolvimento local conduzidas pelos municípios. Inicialmente, o governo federal, em seu processo de redução da estrutura do Estado, transferiu atribuições para os governos municipais. Promulgada a Constituição de 1988, ocorreu a contrapartida desse processo, com o aumento da participação dos municípios na repartição dos recursos fiscais. As palavras de Arretche (1999) sintetizam bem essa nova situação:

Em suma, no Brasil pós-1988, a autoridade política de cada nível de governo é soberana e independente das demais. Diferentemente de outros países, os municípios brasileiros foram declarados entes federativos autônomos, o que implica que um prefeito é autoridade soberana em sua circunscrição. Nessas condições, a redefinição de competências e atribuições da gestão das políticas sociais tem-se realizado sobre as bases institucionais de um Estado federativo, o que significa dizer que o modo pelo qual os governos locais assumem funções de gestão de políticas é inteiramente distinto daquele sob o qual elas foram assumidas no regime militar (ARRETCHE, 1999, p.114).

Esse fato tende a fornecer maior autonomia ao poder público municipal, reconhecidamente mais sensível às demandas locais. Nesse novo contexto, o binômio tecnologia/inovação tem recebido atenção especial em algumas regiões, pela sua capacidade de potencializar o capital social existente em comunidades, organizações e instituições locais, contribuindo significativamente para o desenvolvimento endógeno, regional. Para tanto, torna-se necessário, segundo Mota (2001),

(...) localizar espacialmente as potencialidades e oportunidades produtivas e as interações setoriais, assim como as competências estabelecidas nas regiões, que podem ser indutoras de novos processos de desenvolvimento; é fundamental ampliar e utilizar a competência técnico-científica instalada, seja ela de recursos humanos e/ou laboratoriais, como suporte à competitividade do setor produtivo; é imprescindível, ainda, utilizando-se de novas tecnologias, induzir o surgimento e a disseminação de setores difusores de progresso técnico, observando-se as potencialidades de cada região (MOTA, 2001, p.6). 
O novo papel desempenhado pela esfera pública municipal ante o conjunto de demandas sociais e econômicas de uma região tem exigido de seus gestores competência e criatividade. $O$ tratamento dispensado à problemática tecnológica em algumas localidades ilustra bem esse fato. A restrita capacidade de investimento das instâncias públicas locais tem limitado suas ações como ente financiador. Entretanto, promovem sua condição de articuladoras cuja função é combinar competências e incentivar a constituição de organizações (públicas e privadas) cujas atividades sejam intensivas em tecnologia.

O banco de dados da Organização para Cooperação e Desenvolvimento Econômico sobre programas de apoio à indústria mostra que, a partir da segunda metade dos anos 80 , os gastos públicos destinados ao auxílio ao investimento, de caráter geral, diminuíram principalmente em razão de reformas que reduziram incentivos fiscais. Porém, tal diminuição foi mais do que compensada por um aumento significativo de outras medidas de política que foram reforçadas. Entre estas, devem destacar-se as medidas de caráter regional e de apoio à inovação, as que mais crescem (CASSIOLATO \& LASTRES, 2000, p.240).

\subsection{As incubadoras de empresas como parte dos sistemas locais de inovação tecnológica}

As incubadoras de empresas são parte substancial dos sistemas locais de inovação tecnológica, pois permitem a transferência de tecnologia entre a universidade e o setor produtivo. Nas localidades onde atuam, desenvolvem políticas de apoio às empresas incubadas na gestão tecnológica e, sobretudo, são o centro mais importante da cultura empreendedora da região.

O objetivo das incubadoras é dar suporte a pequenas e microempresas de base tecnológica - que busquem a diversificação e a revitalização econômica, agregando valor aos seus produtos -, viabilizando a interação com centros de ensino e pesquisa, para que a região beneficiada tenha maior produtividade e seja mais competitiva no mercado. Da mesma forma, propiciam o desenvolvimento de novos empreendimentos que sejam financeiramente viáveis e capazes de se adaptar ao mercado após o período de permanência na incubadora. Além disso, apoiam a transformação de empresários potenciais em empresas crescentes e lucrativas e diminuem os riscos dos empreendimentos. Finalmente, contribuem para a revitalização das regiões onde atuam, tendo em vista que favorecem o surgimento de novas empresas e empregos, melhorando a distribuição de renda.

Segundo Bermúdez (2000), as incubadoras de empresas de base tecnológica caracterizam-se como um grupo de negócios de alta tecnologia que oferecem facilidades físicas, possibilitam redes de conhecimentos pessoais, consultorias quanto a um sem-número de necessidades e incentivos que podem tornar realidade o sonho de um empreendedor na área tecnológica.

\section{Procedimentos metodológicos}

Por causa das peculiaridades do tema em análise, optou-se pela pesquisa de natureza qualitativa, cuja principal função é a explicação sistemática de fatos que ocorrem no contexto social, geralmente, relacionados a uma multiplicidade de variáveis (MARTINS, 1994; GODOY, 1995).

Um método de pesquisa considerado adequado para o desenvolvimento de uma investigação qualitativa é o estudo de caso, pois esse tipo de abordagem procura trabalhar com cenários sociais bastantes específicos (ALENCAR, 1999).

Esta investigação é um estudo de caso, uma vez que está circunscrita a uma unidade de estudo, o Programa Municipal de Incubação Avançada de Empresas de Base Tecnológica.

O universo da pesquisa é o município de Santa Rita do Sapucaí, no sul de Minas Gerais, com uma população em torno de 35 mil habitantes. Nos últimos 25 anos, essa região de Minas Gerais sofreu uma drástica mudança, deixando de ser predominantemente agropecuária (produção de café e leite) para tornar-se um dos principais pólos de desenvolvimento tecnológico do país, conhecido como Vale da Eletrônica. 
$\mathrm{Na}$ região, estão 112 empresas de pequeno e médio porte que atuam nos setores eletroeletrônicos, de telecomunicações, informática, automação industrial, matéria-prima e de prestação de serviços. O Vale da Eletrônica gera 6,5 mil empregos - a maioria de nível técnico médio - e em 2003 respondeu por uma receita superior a US\$150 milhões, em que só com a exportação, o faturamento foi de aproximadamente US\$25 milhões. Além disso, o pólo responde por cerca de 50\% do Produto Interno Bruto (PIB) do município, estimado em US\$300 milhões. Em termos do Índice de Desenvolvimento Humano (IDH) da ONU, Santa Rita do Sapucaí se enquadra como de "alto índice".

De acordo com o secretário de Ciência e Tecnologia de Minas Gerais, Olavo Bilac Pinto Neto, há uma política de pleno emprego e de crescente especialização de mão-de-obra em toda aquela região. Segundo o secretário, a articulação inicial entre a academia e empreendedores, para a formação do pólo, hoje, dá lugar a uma aliança cada vez mais sólida entre os governos municipal e estadual. Atualmente, em Santa Rita do Sapucaí há um conjunto de empresas competitivas, preparadas para o desafio do comércio internacional num ambiente econômico global.

A chegada da eletrônica na cidade ocorreu em 1959, com a criação da Escola Técnica de Eletrônica Francisco Moreira Costa (ETE), a primeira do gênero na América Latina. A partir daí, o segmento ganhou importância e novas instituições de ensino foram criadas, destacando-se o Instituto Nacional de Telecomunicações (Inatel), em 1965, e a Faculdade de Administração e Informática, em 1971 (PREFEITURA MUNICIPAL DE SANTA RITA DO SAPUCAI - PMRS, 2002).

\section{Resultados e discussão}

Da perspectiva teórica do apoio e da constituição de iniciativas locais de fomento à inovação, a Prefeitura Municipal de Santa Rita do Sapucaí busca continuamente amparo legal para a concessão de incentivos à expansão industrial de seu município. A pesquisa exploratória mostrou que a prefeitura desenvolveu uma série de ações de apoio ao empreendedorismo, abrangendo desde a concepção do projeto até a construção de sua sede própria, através de um programa denominado Ceempac - Centro Municipal Profissionalizante de Atendimento ao Adolescente e à Criança - desenvolvido pela Secretaria Municipal de Educação, Esporte, Cultura, e Turismo. Desse programa consistem:

\subsection{Incentivos ao empreendimento desde a educação básica}

A história de Santa Rita do Sapucaí tem uma peculiaridade importante. "Foi através do meio acadêmico que se induziram as primeiras empresas de base tecnológica na região", afirma o diretor do Inatel, Wander Wilson Chaves. Segundo ele: "Essa situação do meio acadêmico induzir a criação de empresas fez com que elas passassem a ter uma visão diferenciada - de modernização, de tecnologia, de competitividade, mas, também, um pensamento comunitário, socialmente responsável".

Trata-se de um processo diferente do ocorrido em outras regiões do país, onde a direção era contrária - o pólo industrial é que puxava as instituições de ensino. Até então, não se conhecia nenhuma experiência de um arranjo educacional que atraísse empresas industriais, como aconteceu em Santa Rita. Havia razões para isso. A economia da região era tipicamente agrária, mas as famílias que detinham o poder econômico local nunca se descuidaram da educação, tendo sido criado um sistema educacional com a preocupação de abrir mercado de trabalho para os alunos.

Essa preocupação acabou sendo um incentivo ao espírito empreendedor dos alunos, desde a educação básica. Atualmente, as crianças passam a ter contato com a tecnologia em um sistema de pré-incubação empresarial na escola, através de aulas de informática e empreendedorismo em oficinas especializadas. Diversos laboratórios estão disponíveis para alunos dos ensinos fundamental e médio, com a participação direta dos professores. $\mathrm{O}$ laboratório móvel de informática, com acesso à internet via rádio, beneficia também os alunos da zona rural. Essas ações voltadas à educação, além de serem contempladas pelas políticas públicas, têm o apoio direto das empresas já consolidadas no município e dos institutos de pesquisa de nível superior. Todo o pessoal vinculado 
à Secretaria de Educação é capacitado periodicamente dentro da filosofia da pedagogia empreendedora. Cada aluno da rede municipal de ensino é estimulado a criticar a realidade vivenciada no município. Entretanto, para cada crítica, o aluno deve apresentar uma proposta de solução para o problema em questão.

Os modelos de ensino das instituições (ETE, Inatel e FAI), hoje consagrados no panorama educacional brasileiro, também estão voltados para uma visão de forte aplicação no setor produtivo. Desde o princípio, o objetivo dessas escolas era criar um pólo de formação de recursos humanos para a área de tecnologia. Esse sistema educacional, com características comunitárias, humanísticas e de forte aproximação com o setor empresarial, tornou-se vetor decisivo do processo de industrialização da cidade. Tal fato, aliado a outras características, contribuiu para que desde o início se desenvolvesse o conceito de intenso apoio aos alunos que querem desenvolver seus próprios projetos. Há muitos anos são realizadas feiras tecnológicas nessas instituições, onde, muitas vezes, os projetos dos alunos dão origem a novas empresas.

Com todas essas ações, Santa Rita do Sapucaí apresenta um perfil diferenciado de empreendedores voltados especialmente para a inovação e a criação de empresas de base tecnológica. Esse perfil inovador e tecnológico está calcado no multiculturalismo, no ambiente acadêmico e na interação poder público/escolas/empresariado.

Portanto, as políticas públicas desse município interagem numa cultura empreendedora que envolve arranjos institucionais, fazendo uso direto do poder público, escolas e empresas. Do contrário, o município não alcançaria seu reconhecido sucesso. Em Santa Rita do Sapucaí, a inovação é um processo de busca e aprendizado, partindo do contexto educacional em que, à medida que as interações foram ocorrendo, surgiram arranjos e formatos institucionais e organizacionais específicos, o que estimulou a pesquisa, o desenvolvimento e a geração de oportunidades.

Quando se sabe que o conhecimento circula e se transforma - muitas vezes, dentro da rede formada por empresas, institutos públicos, usuários, universidades e outros atores que participam da geração de uma inovação -, verifica-se que no município estudado isso tem se tornado uma realidade significativa. Isso ocorre pela homogeneização da linguagem dos atores, pela convivência, pela troca de experiências e pela socialização do conhecimento.

Os países cujos indivíduos não se mantiverem em constante aprendizado podem perder a capacidade de criar e até de absorver novas idéias, vendo seu progresso tecnológico diminuir. Dessa forma, o poder público deve promover a educação básica, técnica e a superior. Como argumenta Kim (1998), as políticas públicas devem aumentar os investimentos em educação, antes mesmo de iniciar qualquer programa de industrialização. $\mathrm{O}$ primeiro passo é construir um estoque de capital humano expressivo.

\subsection{A incubadora municipal de empresas}

O estudo de caso foi desenvolvido na Incubadora Municipal de Empresas de Santa Rita do Sapucaí, uma entidade pública sem fins lucrativos, criada em 1-11-1999. Trata-se de uma incubadora de base tecnológica que estabelece parcerias com as principais instituições de ensino do município: a Escola Técnica de Eletrônica Francisco Moreira da Costa (ETE-FMC), a Faculdade de Administração e Informática (FAI) e o Instituto Nacional de Telecomunicações (Inatel). Para viabilizar seu funcionamento a Incubadora Municipal conta com outras parcerias e o apoio de outras entidades, tais como: Sebrae (MG), Secretaria de Estado de Ciência e Tecnologia (SECT) de Minas Gerais, Rede Mineira de Incubadoras (RMI); Associação Nacional de Entidades Promotoras de Empreendimentos de Tecnologias Avançadas (Anprotec), Fundação de Apoio à Pequena e Micro Empresa de Minas Gerais (Fapemig) e a Associação Comercial de Santa Rita do Sapucaí.

Com espaço para abrigar simultaneamente até 10 novos empreendimentos, a Incubadora Municipal de Empresas de Santa Rita do Sapucaí funciona num prédio da Prefeitura Municipal, por um período de dois anos, renovável, com

- salas individuais;

- mobiliário básico; 
- sala de treinamento;

- área de uso comum;

- assessoria e consultoria técnica nas áreas de marketing, vendas, finanças etc.;

- apoio na divulgação;

- infra-estrutura e equipamentos necessários (água, energia, telefone, internet etc.);

- pesquisa e facilitação das linhas de crédito;

- acesso às agências de fomento;

- treinamento em gestão, mercado, tecnologia, etc.;

- custeio de despesas diversas - recepção, fax, etc.; e

- apoio para participação em feiras e eventos diversos.

Além da incubadora municipal, o Inatel e a FAI igualmente mantêm um serviço de incubação de empresas, o que permite ao município dispor de um total de três incubadoras de empresas.

A Incubadora Municipal de Santa Rita do Sapucaí tem como objetivo criar e fortalecer empresas de base tecnológica, representando um mecanismo fundamental para incrementar a geração e a disseminação de novas tecnologias. Até o momento, a incubadora já graduou 11 empresas e conta com 10 empresas residentes, conforme mostrado na Tabela 1.

\section{Tabela 1}

Empresas graduadas e residentes na

Incubadora Municipal de Empresas de Santa Rita do Sapucaí

\begin{tabular}{lclc}
\hline Empresas residentes & $\begin{array}{c}\text { Tempo de } \\
\text { incubação } \\
\text { (meses) }\end{array}$ & Empresas graduadas & $\begin{array}{c}\text { Tempo de } \\
\text { incubação } \\
\text { (meses) }\end{array}$ \\
\hline $\begin{array}{l}\text { 1. Neomera Equipamentos } \\
\text { Eletrônicos }\end{array}$ & 3 & Tecnitron Ltda & 31 \\
\hline 2. RPS Teleinformática & 3 & $\begin{array}{l}\text { Telesystem Indústria Eletrônica } \\
\text { Ltda }\end{array}$ & 21 \\
\hline $\begin{array}{l}\text { 3. Mouse Click Soluções para } \\
\text { Mídia Eletrônica Ltda }\end{array}$ & 26 & Kompytek Representações Ltda & 21 \\
\hline 4. Digital Gás & 3 & Viasat Ltda & 29 \\
\hline $\begin{array}{l}\text { 5. Ralttek Equipamentos } \\
\text { Eletrônicos, Indústria e Comércio }\end{array}$ & 26 & Sectra Ltda & 41 \\
Ltda & 23 & Waysoft & 37 \\
\hline 6. Genno Tecnologia Ltda & 26 & Data Express Ltda & 45 \\
\hline $\begin{array}{l}\text { 7. Codesis Consultoria e } \\
\text { Desenvolvimento de Sistemas Ltda }\end{array}$ & 12 & Exsto Tecnologia Ltda & 3 \\
\hline 8. 3J Tecnologia Eletrônica Ltda & 21 & GWG & 12 \\
\hline 9. Sapucaí NET & 21 & Intelfarm Telecomunicações & 5 \\
\hline $\begin{array}{l}\text { 10. Biosoftware Sistemas Didáticos } \\
\text { Ltda }\end{array}$ & & Proagilen Consultoria, & 18 \\
\hline
\end{tabular}

Fonte: www.prointec.com.br 
Uma importante conquista da incubadora municipal foi ter ganho o Prêmio Anprotec 2003 de melhor incubadora brasileira de base tecnológica. O prêmio veio coroar o trabalho e a dedicação de uma equipe de reconhecida capacidade. Ao mesmo tempo, é inspiração e incentivo a essa iniciativa de indiscutível cunho social, pelo aumento de empresas sólidas, incremento na oferta de empregos, do dinheiro circulante e da arrecadação de impostos; o que se reflete na qualidade de vida da comunidade.

De acordo com o prefeito de Santa Rita do Sapucaí, Jefferson Gonçalves Mendes, a Incubadora Municipal de Empresas de Base Tecnológica é a iniciativa mais importante da prefeitura. Ele lembra que as 10 empresas incubadas recebem não apenas orientação para seus projetos, mas também assessoria jurídica; acrescentando que, mesmo depois de graduadas, continuam recebendo ajuda. Em contrapartida, o município aumentou sua arrecadação e na cidade praticamente não há desemprego. Ainda de acordo com o prefeito, a qualidade de vida melhorou, e tanto o nível salarial quanto a geração de riquezas aumentaram, possibilitando ao município investir mais em educação, saúde e habitação. Em relação à moradia, a prefeitura fornece gratuitamente o lote e todo o material necessário para a família construir sua casa, o que já beneficiou cerca de 10 mil pessoas.

Hoje, empresários, governantes e educadores acreditam que essa bem-sucedida experiência é um exemplo nacional que precisa ter continuidade. Nesse sentido, é necessário que haja integração entre poder público, empresários e academia para que o pólo tecnológico seja consolidado. O poder público precisa ter políticas de desenvolvimento e de ciência e tecnologia para o país como um todo. Já, os empresários devem aperfeiçoar continuamente seus negócios, buscando informações e inovações para poderem sobreviver no mercado. Da parte da academia, é preciso intensificar a indução do que se acredita em termos de visão de mundo, para que as empresas sejam apoiadas nos seus programas de capacitação e diferenciadas, buscando essa visão mais social. Trata-se, portanto, de institucionalizar e sistematizar um novo tipo de industrialização.

Já foram registrados vários movimentos de cooperação envolvendo agentes de fomento e órgãos oficiais de investimentos, além da busca por capital privado. No início de 2003, pela segunda vez, foi realizado em Santa Rita, o InvestVale, um Encontro empresarial realizado pelo Inatel- Instituto Nacional de Telecomunicações destinado a investidores que procuram boas chances de investir em empresas de base tecnológica na região. A iniciativa contribui assim para o desenvolvimento do Pólo Tecnológico de Santa Rita do Sapucaí e região, e também do estado e País., que reuniu 11 empresas incubadas, incubadoras da cidade, além de 32 investidores de capital de risco, entre os quais a Stratus Investimentos (empresa paulista de investimentos, direcionados para empresas com grande potencial de crescimento), interessados em desembolsar até $\mathrm{R} \$ 1$ milhão em empresas estratégicas.

Outro empreendimento que vale ressaltar é o Centro de Orientação Empresarial de Santa Rita do Sapucaí, resultado de uma parceria entre a prefeitura e a iniciativa privada. Esse centro foi instalado na periferia da cidade para receber um grupo de micros e pequenas empresas. Seu objetivo é atender às necessidades de empresas graduadas no sistema local de incubação, completando a sua inserção no mercado. Ocupa uma área de 8.372 m2 e, com a aprovação da Câmara Municipal, os 13 lotes ali existentes receberam calçamento, foram asfaltados e tiveram instaladas redes de água, luz e esgoto; infra-estrutura que foi doada às empresas que ali estão operando e que respondem pela geração de 400 postos de trabalho diretos. A prefeitura subsidia o aluguel de imóveis para empresas recém-graduadas por incubadoras e faz doações de terrenos para que elas possam construir suas fábricas. Até o momento, a prefeitura já doou cerca de 50 terrenos. Nele estão localizados o Sindicato das Indústrias de Aparelhos Elétricos, Eletrônicos e Similares do Vale da Eletrônica e a Associação Industrial de Santa Rita do Sapucaí. Ali, também funcionam um showroom de produtos, salas de treinamento e um posto médico e odontológico. "Escolhemos uma região pobre da cidade para abrir uma oportunidade de trabalho para os moradores. Houve, ainda, a preocupação com a imagem do local e o centro recebeu um cuidadoso projeto paisagístico para atrair clientes", explica o prefeito Jefferson Mendes.

Atualmente, está sendo construído o Centro Empresarial I que vai dar vida à unidade do Sesi/Senai, equipada com piscina, quadra esportiva e restaurante coletivo. O investimento é de R \$1 milhão, a car- 
go da Federação das Indústrias de Minas Gerais (Fiemg). No bairro vizinho, também está sendo erguido o Centro Empresarial II, com uma área de $18.000 \mathrm{~m} 2$. A expectativa é de que o empreendimento atraia mais 30 empresas de porte médio e gere mais 600 postos de trabalho direto.

Como aporte final da pesquisa, verifica-se que as mudanças em Santa Rita do Sapucaí não ocorreram repentinamente e, sim, de forma gradativa, ao longo de diversas administrações. Como já foi dito, a construção do pólo tecnológico não tem sido um esforço isolado, mas foi conseguido com a formação de alianças e parcerias, o que reflete uma tendência mundial.

As atuais políticas públicas do município e suas estratégias de inovação refletem de maneira mais clara os objetivos voltados para o desenvolvimento equânime e progressivo daquela localidade. Os incentivos por parte do governo municipal e a integração entre empresas e universidades constituem uma ação estratégica no que diz respeito ao desenvolvimento do pólo tecnológico. Isso viabiliza a implantação de novos empreendimentos e contribui para o aumento da competitividade no mercado global.

\section{Conclusão}

Este artigo mostrou o potencial existente numa parceria do poder público com outras instituições, na busca pela inovação tecnológica. Os índices do município de Santa Rita de Sapucaí mostram o quão promissor são essas parcerias, não somente quanto à sobrevivência de um empreendimento, mas também no que diz respeito ao bem-estar social.

A incubadora de empresas pode ser uma alternativa para tentar amenizar o desemprego estrutural existente hoje em dia no Brasil. A inovação tecnológica pode causar um "enxugamento" de postos de trabalhos, mas se incentivada e apoiada pelo poder público, através de projetos de fomento, o número de novos empreendimentos é compensador. Conseqüentemente, há crescimento da renda e melhora na qualidade de vida, o que resgata a cidadania e promove a justiça social. 


\section{Referências bibliográficas}

ALENCAR, E. Introdução à metodologia de pesquisa social. Lavras: UFLA/Faepe,1999. 105p.

ARRETCHE, M. T. S. Políticas sociais no Brasil: descentralização em um Estado federativo. Revista Brasileira de Ciências Sociais, v.14, n.40, jun.1999.

BELL, M.; PAVITT, K. Technological accumulation and industrial growth: contrasts between developed and developing countries. Industrial and Corporate Change, v.2, n.2, 1993.

BERM ÚDEZ, L. A. Incubadoras de empresas e inovação tecnológica: o caso de Brasília. Parcerias Estratégicas - Revista do Centro de Estudos Estratégicos do Ministério de Ciência e Tecnologia, Brasília, DF, n.8, maio 2000.

BETZ, F. Strategic technology management. New York: McGraw-Hill, 1993.

BRASIL. Ministério da Ciência e Tecnologia. Secretaria de Política de Informática e Tecnologia. Resultados da Lei de Informática - uma avaliação. Brasília, DF, 2004.

CASSIOLATO, J. E.; LASTRES, M. H. M. Sistemas de inovação: políticas e perspectivas. Parcerias Estratégicas - Revista do Centro de Estudos Estratégicos do Ministério de Ciência e Tecnologia, Braślia, DF, n. 8, p.237-255, maio 2000.

DENIOZOS, D. Steps for the introduction of technology management in developing economies: the role of public government. Technovation, v.14, n.3, p.197-203, 1994.

DRUCKER, P. Desafios gerenciais para o século XXI. São Paulo: Pioneira, 1999.

FONSECA, R. Inovação tecnológica e o papel do governo. Parcerias Estratégicas - Revista do Centro de Estudos Estratégicos do Ministério de Ciência e Tecnologia, Braślia, DF, n.13, dez. 2001.

FREEMAN, C; SOETE, L. The economics of industrial innovation. London: Pinter Publisher, 1997.

GODOY, A. S. Introdução à pesquisa qualitativa e suas possibilidades. Revista de Administração de Empresas, São Paulo, v.35, n.2, p.5763, mar./abr. 1995.

GOUSSEVSKAIA, A.; RODRIGUES, S. B. Mudança na administração de tecnologia no setor de telecomunicações: estudo de caso da Telemig. In: ENCONTRO DA ANPAD, 24., 2000, Curitiba. Anais... Curitiba, 2000.

GUIMARÃES, F. C. M. S. A. A política de incentivo à inovação: inovação, desenvolvimento econômico e política tecnológica. Parcerias Estratégicas - Revista do Centro de Estudos Estratégicos do Ministério de Ciência e Tecnologia, Brasília, DF, n.8, maio 2000.

KIM , L. Imitation to innovation - the dynamics of Korea's technological learning. Boston: Harvard Business School, 1997.

LACERDA, A. C. et al. Tecnologia: estratégia para a competitividade. São Paulo: Nobel, 2001.

MARTINS, G. A. Manual para elaboração de monografias e dissertações. 2. ed., São Paulo: Atlas, 1994.

MINISTÉRIO DA FAZENDA E DA RECEITA DO CANADÁ. The Federal System of income Tax Incentives for Scientific Research and Experimental Development: Evaluation Report. Canada: Ministério da Fazenda e da Receita, Dezembro de 1997.

M OTA, T. L. N. G. Sistema de inovação regional e desenvolvimento tecnológico. Parcerias Estratégicas - Revista do Centro de Estudos Estratégicos do Ministério de Ciência e Tecnologia, n.11, jun. 2001.

NICOLSKY, R. Inovação tecnológica industrial e desenvolvimento sustentado. Parcerias Estratégicas - Revista do Centro de Estudos Estratégicos do Ministério de Ciência e Tecnologia, n.13, dez. 2001.

NONAKA, I.; TAKEUCHI, H. Criação de conhecimento na empresa - como as empresas japonesas geram a dinâmica da inovação. Rio de Janeiro: Campus, 1997.

ORGANIZATION FOR ECONOMIC COOPERATION AND DEVELOPMENT - OECD. Proposed guidelines for collecting and interpreting technological innovation data: Oslo Manual. Paris, 1992.

PORTER, M. E. Vantagem competitiva. Rio de Janeiro: Campus, 1989.

The competitive advantage of nations. New York: Free Press, 1990.

PREFEITURA MUNICIPAL DE SANTA RITA DO SAPUCAI - PMSRS. Política de Inovação Tecnológica no Município de Santa Rita do Sapucaí - Minas Gerais. Relatório: Premio Mário Covas para o Prefeito Empreendedor. Santa Rita do Sapucaí- MG: Incubadora Municipal de Empresas de Base Tecnológica de Santa Rita do Sapucaí, 2002.

REIS, D. R.. Gestão da inovação tecnológica. Barueri: Manole, 2004.

SALLES, W. L. F.; HASENCLEVER, L. Avaliação da política pública de desenvolvimento tecnológico industrial e agropecuário - PDT/PDTA. In: ENCONTRO DA ANPAD, 23., 1999, Foz do Iguaçu. Anais... Foz do Iguaçu, 1999.. 
SÁNCHEZ, T. W. S; PAULA, M. C. de S. Desafios institucionais para o setor de ciência e tecnologia: o sistema nacional de ciência e inovação tecnológica. Parcerias Estratégicas - Revista do Centro de Estudos Estratégicos do M inistério de Ciência e Tecnologia, n.13, dez. 2001.

SANTOS JÚNIOR, W. L.; PAULA, G. M. Sistema Nacional de Inovações e Gestão da Política de C\&T: lições do caso canadense. In; ENCONTRO DA ANPAD, 24., Curitiba Anais... Curitiba, 2000.

SCHUMPETER, J. A. Teoria do desenvolvimento econômico: uma investigação sobre lucros, capital, crédito, juro e ciclo econômico. São Paulo: Abril Cultural, 1982. (Os economistas). 